\title{
Annotated expressed sequence tags for studies of the regulation of reproductive modes in aphids
}

\author{
D. Tagu ${ }^{\mathrm{a}, *}$, N. Prunier-Leterme ${ }^{\mathrm{a}}$, F. Legeai $^{\mathrm{b}}$, J.-P. Gauthier $^{\mathrm{a}}$, A. Duclert $^{\mathrm{b}}$, \\ B. Sabater-Muñoz ${ }^{\text {a }}$, J. Bonhomme ${ }^{\text {a }}$, J.-C. Simon ${ }^{\text {a }}$ \\ a INRA Rennes, UMR INRA-AGROCAMPUS BiO3P, BP 35327, Le Rheu F-35653, cedex, France \\ ${ }^{\mathrm{b}}$ INRA, URGI-Genoplante Info, Infobiogen, 523 place des Terrasses, F-91000, Evry, France
}

Received 15 March 2004; received in revised form 23 April 2004; accepted 17 May 2004

\begin{abstract}
The damaging effect of aphids to crops is largely determined by the spectacular rate of increase of populational expansion due to their parthenogenetic generations. Despite this, the molecular processes triggering the transition between the parthenogenetic and sexual phases between their annual life cycle have received little attention. Here, we describe a collection of genes from the cereal aphid Rhopalosiphum padi expressed during the switch from parthenogenetic to sexual reproduction. After cDNA cloning and sequencing, 726 expressed sequence tags (EST) were annotated. The $R$. padi EST collection contained a substantial number (139) of bacterial endosymbiont sequences. The majority of $R$. padi cDNAs encoded either unknown proteins (56\%) or housekeeping polypeptides (38\%). The large proportion of sequences without similarities in the databases is related to both their small size and their high GC content, corresponding probably to the presence of $5^{\prime}$-unstranslated regions. Fifteen genes involved in developmental and differentiation events were identified by similarity to known genes. Some of these may be useful candidates for markers of the early steps of sexual differentiation.
\end{abstract}

(C) 2004 Elsevier Ltd. All rights reserved.

Keywords: Aphid; cDNA; EST; Development; Reproduction

\section{Introduction}

Aphids are plant-sucking insects which cause serious damage on most cultivated and ornamental plants world-wide. They affect plant growth either directly by depletion of sucrose and amino-acids content, or indirectly, especially by plant virus transmission. The impact of aphid on crops is largely determined by their high rates of multiplication and dispersal conferred by both (1) a peculiar mode of reproduction which is cyclically parthenogenetic (i.e. alternance of many parthenogenetic generations and a single sexual generation within the annual life cycle) and (2) an amazing phenotypic plasticity - called polyphenism. Aphid polyphenism allows one single genotype (a clone) to adapt to

\footnotetext{
* Corresponding author. Tel.: +33-223-48-51-65; fax: +33-223-4851-50.

E-mail address: tagu@rennes.inra.fr (D. Tagu).
}

rapidly changing environmental conditions by expressing multiple and often morphologically distinct phenotypes. Up to now, most effort has focused on the ecological factors and the physiological changes responsible for this aphid polyphenism, but its molecular basis remains largely unexplored. Changes in day length can induce the switch from parthenogenetic to sexual reproduction within an aphid colony (Dixon, 1998) and the length of the dark phase is one of the key factors determining the reproductive outcome (reviewed by Hardie and Nunes, 2001). Perception by aphids of photoperiodic changes is independent of eyes and localised illuminations of the head capsule indicated that the central dorsal region was most sensitive to the photoperiodic variations. It is probable that proteins involved in photoperception (e.g. opsins) and phototransduction (e.g. arrestins) are localised in that brain region but nothing is known about these putative photoreceptors and phototransducers in aphids. Early 
experiments performed by microcautery disruption of cells indicated a group of clock-neurosecretory cells in the protocerebrum which were involved in the photoperiodic response of aphids. The first aphid gene regulated by reproductive polyphenism has been recently identified; it corresponds to a putative amino acid transporter in GABAergic neurons which could play a role in the generation and modulation of circadian rhythmicity (Ramos et al., 2003). Triggering the sexual response of aphids to day-length must result from several cascades of events which are far from being understood. Unravelling the nature of the molecular events underpinning polyphenisms in aphids is thus becoming a necessary step towards (i) the elucidation on the coexistence of sexual and asexual reproductive modes in aphids and (ii) the development of innovative control strategies against these important crop pests.

Expressed sequence tags (ESTs) have become an effective means of gene discovery and therefore, in an effort to create a resource for gene discovery in aphids and to begin the characterization of their genetic complement, we have generated ESTs from the aphid Rhopalosiphum padi. This aphid causes serious damages to most cereals world-wide and is an efficient vector of cereal and barley yellow dwarf viruses (Gray and Gildow, 2003). Here, we describe the annotation of 726 new ESTs together with $4358 \mathrm{mRNA}$ and EST sequences from different aphid species found in public DNA sequence databases.

\section{Materials and methods}

The cyclically parthenogenetic line, h3 (i.e. that alternates several parthenogenetic generations and a single sexual generation within the annual life cycle) of $R$. padi was isolated at Rennes (France) in 1992 from its winter host, the bird cherry tree, Prunus padus and has been reared since on wheat in the laboratory. It was maintained in conditions of continuous parthenogenetic reproduction under long photoperiod (16-h light/8-h dark) and warm temperature $\left(18{ }^{\circ} \mathrm{C}\right)$. In order to enrich the cDNA library in transcripts upregulated under sexual-reproductive mode, insects were placed in sex-induction conditions using a standard protocol (Simon et al., 1991) (Fig. 1). Briefly, fourth instar parthenogenetic nymphs (N4) were transferred on wheat seedlings (6 nymphs per plant) under short photoperiod and low temperature (10-h light/14-h dark at $12{ }^{\circ} \mathrm{C}$ ). After 8 days, they became adults and gave birth to first instar parthenogenetic larvae (L1). About 100 of these larvae were individually transferred to new wheat seedlings. After two moults, third instar larvae (L3) were collected and immediately frozen in liquid nitrogen, and kept at $-80{ }^{\circ} \mathrm{C}$ until use. These L3 larvae corresponded to future wingless parthenogenetic females induced to produce sexual forms (Fig. 1).

Total RNA from 74 whole-L3 larvae (see above) was extracted using the RNeasy Plant Mini Kit (Qiagen, Hilden, Germany) in the RTL extraction buffer, following the manufacturer instructions. cDNA synthesis and cloning were performed with the Creator ${ }^{(i m}$ Smart ${ }^{(\mathbb{m}}$ cDNA Library Construction Kit (BD Biosciences Clontech, Palo Alto, CA, USA). Briefly, enriched fulllength double-stranded cDNA were obtained by RT-PCR and ligated into the pDNR-LIB plasmid. Ligation products were electroporated in electrocompetent Escherichia coli TOP10 (Invitrogen, Paisley, UnitedKingdom) cells. Bacterial colonies $(n=1056)$ were inoculated into 96-well plates containing selective LB medium and $10 \%(\mathrm{v} / \mathrm{v})$ glycerol, and grown overnight in stand culture at $37{ }^{\circ} \mathrm{C}$. Backup plates were also created. Plates were stored at $-80{ }^{\circ} \mathrm{C}$.

Polymerase chain reaction (PCR) was performed in $15 \mu \mathrm{l}$ of final volume from $1 \mu \mathrm{l}$ of defrosted bacterial glycerol stock as template and pDNR-lib forward primer (5'-GCCGCATAACTTCGTATAGCA-3 $\left.{ }^{\prime}\right)$ and pDNR-lib reverse primer (5'-CCAGGATCTCCTAGGGAAACA-3') at $0.2 \mu \mathrm{M}$ final concentration. The PCR consisted of $94{ }^{\circ} \mathrm{C}$ for $2 \mathrm{~min}, 94{ }^{\circ} \mathrm{C}$ for $30 \mathrm{~s}$, $57{ }^{\circ} \mathrm{C}$ for $30 \mathrm{~s}, 72{ }^{\circ} \mathrm{C}$ for $2 \mathrm{~min}$ for 30 cycles and a final extension at $72{ }^{\circ} \mathrm{C}$ for 4 min (PCR Express, HybaidPromega, Madison, WI, USA). A $1 \mu$ aliquot of each reaction was analysed on a $1 \%$ agarose gel and stained with ethidium bromide for the control of size and quality of the PCR products. Excess primers and nucleotides were removed by filtration on Sephadex (SigmaSpin Post-Reaction Clean-Up Plates Kit, Sigma, St Louis, Missouri, USA). A $1 \mu$ aliquot of each reaction was analysed on a $1 \%$ agarose gel and stained with ethidium bromide for the determination of the concentration of the PCR products. The resulting purified PCR products were then rearranged in 96-well plates and used as templates (30-50 ng) for a sequencing reaction using $0.5 \mathrm{mM}$ of the pDNR-lib forward primer with the ABI Prism BigDye v3.1 sequencing kit (ABI, Foster City, CA, USA). Sequencing reactions were performed at $94{ }^{\circ} \mathrm{C}$ for $1 \mathrm{~min}, 94{ }^{\circ} \mathrm{C}$ for $15 \mathrm{~s}, 57{ }^{\circ} \mathrm{C}$ for $7 \mathrm{~s}, 60{ }^{\circ} \mathrm{C}$ for $4 \mathrm{~s}$ for 50 cycles (PCR Express, HybaidPromega, Madison, WI, USA). The products of the sequencing reaction were purified by filtration on Superfine G-50 (Amersham Pharmacia Biotech), using the MultiScreen system (Millipore, Billerica, MA, USA). Samples were eluted in water and ready for capillary electrophoresis separation and detection by the automated multicapillary sequencer (AB 3100, Applied Biosystem, Foster City, CA, USA) at the sequencing facilities of OUEST-Genopole ${ }^{\circledR}$ (Roscoff, France). The name given to each EST corresponds to the name of the cDNA library (RpL3i for 


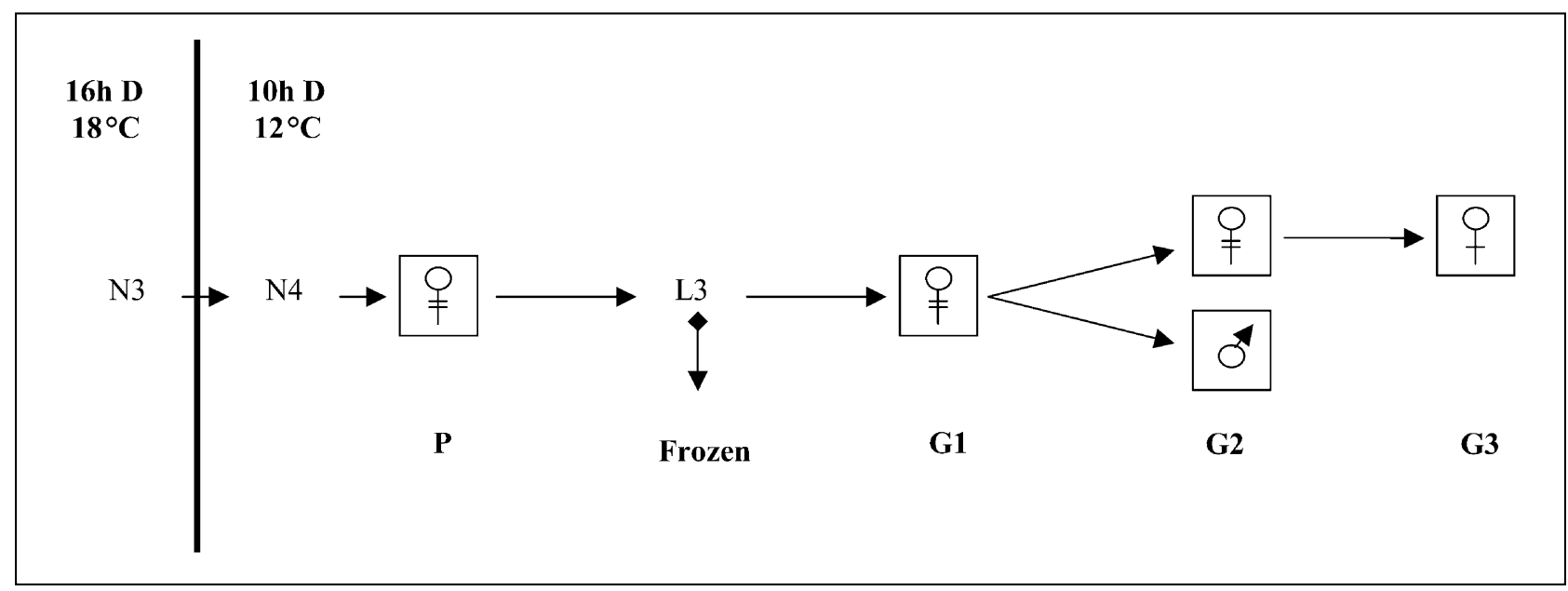

Fig. 1. Induction of sexual reproduction in Rhopalosiphum padi. This diagram follows the same denomination and representation as proposed by Ramos et al. (2003) for the pea aphid Acyrthosiphon pisum in order to facilitate comparison between the two species. Fourth instar parthenogenetic nymphs (N4) were transferred on wheat seedlings under short photoperiod and low temperature. Parthenogenetic adult (P) gave birth to first instar parthenogenetic larvae. After two moults, third instar larvae (L3) were collected and immediately frozen in liquid nitrogen. These L3 larvae corresponded to future wingless parthenogenetic females (G1) induced to produce (G2) males and winged parthenogenetic females (gynoparae) which will produce sexual females (G3). Adult stages are indicated in boxes.

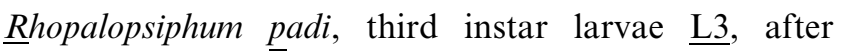
short-day induction), followed by the Roman number of the microplate, the letter of the row in the microplate and the Arabic number of the column in the microplate (eg: RpL3i-I-A1). Sequences have been deposited to GenBank database under the accession numbers CF799941-CF800414.

Full length sequences of 3 cDNA clones encoding proteins involved in differentiation or developmental processes were obtained sequencing both strands of the corresponding cDNA by designing internal specific primers. For each cDNA, assembly was performed by BioEdiT (http://www.mbio.ncsu.edu/BioEdit/bioedit.html) and alignments by Multalin (http://prodes. toulouse.inra.fr/multalin/multalin.html).

Using Phred (Ewing et al., 1998; Ewing and Green, 1998) as a base caller and cross-match (unpublished, see http://www.phrap.org), vectors, adaptors and low quality extremities of the sequences extracted from the ABI chromatograms were clipped out: 12 bases with a phred quality value under 10 on a window of $30 \mathrm{bp}$ length, or stretch of $>15 \mathrm{~A}$, were used as a cut-off.

A total of 53 public EST and mRNA sequences from different aphid species (AF420231, AB005262, AB016720, AB039958, AB051572, AF165428, AF287291, AF411453, AF411454, AF411455, AF412814, AF412815, AF435075, AF448802, AF502081, AF502082, AF502083, AF502084, AF502397, AF527785, AF527786, AF527787, AJ489298, AJ457193, AY049740, AY162274, AY162275, AY217540, AY217542, AJ131759, AJ131760, AJ236786, AJ236787, AJ236788, AJ250348, AJ251838, AJ496197, X74554, X74555, X81887, X81888, AF233239, AF233241, AF233242, AF233243, AF233244, AF233245, AF233246,
AF233247, AF233248, AF527783, AF527784, AF420231) as well as related information (library, tissue, development stage, vector...) were extracted from dbEST and EMBL. ESTs $(n=4304)$ from the brown citrus aphid Toxoptera citricida were extracted from Genbank's dbEST (CB814527-CB814982, CB832665-CB833296, CB854878CB855147, CB909714-CB910020, CB936196-CB936346, CB449954-CB450759).

From all this collection, rRNA sequences, E. coli and yeast sequences were eliminated after identification (cross-match with a score $>100$ ) against an invertebrate ribosomal sequence library (extracted from Genbank), or complete corresponding genomes. As aphids live in symbiosis with Buchnera bacteria (Baumann et al., 1995), R. padi ESTs were compared to the Buchnera sp. APS genome (http://buchnera.gsc.riken.go.jp/) (Shigenobu et al., 2000) and those presenting a crossmatch with a score $>100$ were eliminated.

The remaining sequences were clusterized using Biofacet (Glémet and Codani, 1997), based on a criteria of $96 \%$ similarity over $80 \mathrm{bps}$. Clusters served for contig alignment and a consensus sequence was attained using $\mathrm{CAP}_{\mathrm{AP}}$. The consensus were annotated through a NCBI-blast v2.2.6 by BLASTX against SP-Trembl (version 24): only hits with an $E$-value $<1.0 \times 10^{-5}$ were used for annotation. Two different contig sessions were created: one called " $R$. padi" made off $R$. padi ESTs and the $53 \mathrm{mRNA}$ aphid sequences, and the second combining the " $R$. padi" contig version with the retrieved $T$. citricida ESTs.

A relational database was set up in order to store sequences and annotations, as well as links between 
sequences, clusters, contigs and libraries (Samson et al., 2003). To freely access these data, a web interface (http://urgi.infobiogen.fr///Projects/GPiDB/Interface/) was developed to allow users to get information on sequences, contigs, clusters (e.g. consensus, origin of its members, alignment, annotation, availability of the clone) and libraries (e.g. type, tissue, development stage). A tutorial is available on line (http://urgi.infobiogen.fr////Projects/GPiDB/Interface/gp_est_tutorial.html) which describes how to manipulate the different tools. Data can thus be viewed directly by sequence names or keywords to check for annotation, to execute personalized annotation tasks (ClustalW, Blast, Primer3), and to access to graphical visualization of the contigs (Samson et al., 2003). The whole set of sequences can be downloaded at http://urgi.infobiogen.fr///Projects/GPiDB/Interface/ for personal convenience. Annotation of the two different contig sessions was facilitated by a link to the GeneOntology (The Gene Ontology Consortium, 2001) through the AmiGO browser (http://www.godatabase.org/cgi-bin/ go.cgi).

Codon frequencies were determined for sequences having a hit. First, sequences showing a frameshift (hits on different frames) have been removed from the set. Then, the putative open reading frames (ORFs) were determined as being the larger one from the first codon (ATG) to the first stop codon. Putative ORF were clustered by cellular functions (following the results of annotation, see above and Table 1) and codon usage was calculated for all the putative ORF belonging to one cellular function using EMBoss cusP. Finally, codon usage was compared between cellular functions, by using EMBoss CODCMP.

\section{Results and discussion}

The $R$. padi cDNA library was constructed from total RNA extracted for whole L3 larvae produced under a short photoperiod regime (Fig. 1). About 200,000 bacterial colonies were obtained, and 1056 bacteria were individually kept as glycerol stocks. The average size of the cDNAs was $750 \mathrm{bp}$. About $30 \%$ of the amplified inserts were not sequenced either because of their small size (less than $500 \mathrm{bp}$ including $478 \mathrm{bp}$ of vector) or because of the presence of two amplified fragments detected after gel electrophoresis. Further analyses demonstrated that double bands were related either to the presence of two different bacterial colonies in the same glycerol stock, or to the annealing of primers within the cDNA (data not shown). A total of 726 sequences were obtained from the $5^{\prime}$ end of the selected cDNAs. The mean length of these sequences was $288 \mathrm{bp}$, and the median was $308 \mathrm{bp}$. The longest sequence was $604 \mathrm{bp}$. After the filtering of vector and adaptor sequences, 122 sequences shorter than $80 \mathrm{bp}$ were removed (17\% of the ESTs). ESTs identified as rRNA (four sequences) were also eliminated. Neither yeast nor $E$. coli contaminants were found. The endosymbiotic bacteria Buchnera are located in the abdominal part of aphids in a specific structure called a bacteriocyte (Baumann et al., 1995). Buchnera sequences (e.g. ketol-acid reductoisomerase, GTP-binding protein, porin, chaperonin) present in the $R$. padi EST collection were removed (139 sequences corresponding to $19 \%$ of the ESTs). Regions in the AT-rich bacterial DNA or RNA (probably co-extracted with the total aphid RNA) were probably able to act as a template for the olido(dT) primering during first strand cDNA synthesis. The final set of $R$. padi ESTs contained 461 sequences. The 4304 ESTs of the brown citrus aphid, T. citricida retrieved from dbEST (Hunter et al., 2003) were treated and edited by the same procedures: one EST corresponding to E. coli DNA, two ESTs from Buchnera and 13 ESTs of small size were eliminated. This T. citricida EST collection,--prepared from polyA RNA of whole aphids - was nearly not contaminated with Buchnera sequences, indicating that purification of mRNA might limit the risk of cloning and sequencing endosymbiont DNA.

Clusters and contigs were then produced with the $461 R$. padi sequences plus the 53 mRNA sequences found in the public databases from various aphid species (Acyrthosiphon pisum, Aphis fabae, A. gossypii, $A$. nerii and Myzus persicae): this " $R$. padi contig" corresponds to version 1 of contig (see Materials and methods) at http://urgi.infobiogen.fr///Projects/ GPiDB/Interface/. Among these 514 aphid sequences, 288 sequences were unique and the other 226 ESTs grouped in 73 contigs. The total of contigs was thus $361(288+73)$. The number of ESTs in each contig ranged from 1 (288 contigs) to 13 (one contig). Fifty two sequences from the 53 extracted from public databases did not match to $R$. padi ESTs. Only one contig (CTG_RP_63.1-RpL3i-I-F1, encoding the ribosomal protein $\mathrm{S} 4)$ grouped ESTs from $R$. padi with an aphid (Aphis gossypii) mRNA sequence from the public databases. Therefore, this set of ESTs represents up to 361 unique aphid contigs (or unigenes) from 514 sequences and, with one exception, is composed with sequences from one aphid species. This corresponds to a redundancy of $44 \%$ (number of ESTs in contigs/total number of ESTs) which is in the range of other insect EST collections (Mita et al., 2003). A high redundancy within the $R$. padi sequences was found for the ribosomal proteins (housekeeping proteins). The second contig (version 2 at http://urgi.infobiogen.fr///Projects/ GPiDB/Interface/) put together these 514 aphid sequences and the 4288 ESTs from $T$. citricida (Hunter et al., 2003). This set formed 2457 contigs. More than half (253) of the 514 " $R$. padi contigs" did not group 
Table 1

R. padi EST sequence similarities and abundance

\begin{tabular}{|c|c|c|c|c|c|}
\hline $\begin{array}{l}\text { Contig name per } \\
\text { category }\end{array}$ & Protein homologue & Species & Accession number & Blast $E$-value & $\begin{array}{l}\text { EST } \\
\text { abundance }\end{array}$ \\
\hline Chaperonin & & & & & 7 \\
\hline $\begin{array}{l}\text { CTG_RP_59.1- } \\
\text { RpL3i-I-F10 }\end{array}$ & HSC70 & Trichoplusia ni & Q94805 & $8.0 \times 10^{-38}$ & 2 \\
\hline $\begin{array}{l}\text { CTG_RP_100.1- } \\
\text { RpL3i-I-F2 }\end{array}$ & Stress-induced phosphoprotein 1 & Mus musculus & Q8BPH3 & $4.0 \times 10^{-29}$ & 1 \\
\hline $\begin{array}{l}\text { CTG_RP_177.1- } \\
\text { RpL3i-IV-H7 }\end{array}$ & 90-kDa heat shock protein HSP83 & Spodoptera frugiperda & Q9GQG6 & $3.0 \times 10^{-15}$ & 1 \\
\hline $\begin{array}{l}\text { CTG_RP_195.1- } \\
\text { RpL3i-IX-E6 }\end{array}$ & $70 \mathrm{kDa}$ heat shock protein & Bactrocera tau & Q867Z1 & $1.0 \times 10^{-30}$ & 1 \\
\hline $\begin{array}{l}\text { CTG_RP_337.1- } \\
\text { RpL3i-XI-C10 }\end{array}$ & Heat shock $70 \mathrm{kDa}$ protein cognate & Bombyx mori & O76180 & $2.0 \times 10^{-25}$ & 1 \\
\hline $\begin{array}{l}\text { CTG_RP_341.1- } \\
\text { RpL3i-XI-D2 }\end{array}$ & $\begin{array}{l}\text { T-complex protein } 1 \text { gamma } \\
\text { subunit }\end{array}$ & Lepeophtheirus salmonis & Q9U6Z3 & $2.0 \times 10^{-29}$ & 1 \\
\hline Differentiation & & & & & 16 \\
\hline $\begin{array}{l}\text { CTG_RP_43.1- } \\
\text { RpL3i-III-D8 }\end{array}$ & Chemosensory protein & Leucophaea maderae & Q8MTC3 & $6.0 \times 10^{-23}$ & 2 \\
\hline $\begin{array}{l}\text { CTG_RP_75.1- } \\
\text { RpL3i-I-A2 }\end{array}$ & bgen & Drosophila melanogaster & NM_166627.1 & $3.0 \times 10^{-13}$ & 1 \\
\hline $\begin{array}{l}\text { CTG_RP_90.1- } \\
\text { RpL3i-I-D10 }\end{array}$ & $\begin{array}{l}\text { CG17661 protein (programmed cell } \\
\text { death) }\end{array}$ & Drosophila melanogaster & Q9VMB9 & $9.0 \times 10^{-43}$ & 1 \\
\hline $\begin{array}{l}\text { CTG_RP_112.1- } \\
\text { RpL3i-II-A6 }\end{array}$ & $\begin{array}{l}\text { CG12908 protein (epidermal } \\
\text { growth factor) }\end{array}$ & Drosophila melanogaster & Q9V5J7 & $3.0 \times 10^{-24}$ & 1 \\
\hline $\begin{array}{l}\text { CTG_RP_122.1- } \\
\text { RpL3i-II-F11 }\end{array}$ & Similar to pelota homolog & Danio rerio & Q7ZWC4 & $5.0 \times 10^{-9}$ & 1 \\
\hline $\begin{array}{l}\text { CTG_RP_128.1- } \\
\text { RpL3i-II-H8 }\end{array}$ & CG17870-PF (14-3-3 protein) & Drosophila melanogaster & Q8MKV5 & $7.0 \times 10^{-20}$ & 1 \\
\hline $\begin{array}{l}\text { CTG_RP_147.1- } \\
\text { RpL3i-III-F4 }\end{array}$ & Exuperantia 1 & Drosophila miranda & Q9GNF9 & $6.0 \times 10^{-20}$ & 1 \\
\hline $\begin{array}{l}\text { CTG_RP_157.1- } \\
\text { RpL3i-IV-B2 }\end{array}$ & Septin A & Xenopus laevis & Q9DE33 & $2.0 \times 10^{-7}$ & 1 \\
\hline $\begin{array}{l}\text { CTG_RP_168.1- } \\
\text { RpL3i-IV-F2 }\end{array}$ & $\begin{array}{l}\text { CG12139 protein (lipophorin } \\
\text { receptor) }\end{array}$ & Drosophila melanogaster & Q9W343 & $2.0 \times 10^{-51}$ & 1 \\
\hline $\begin{array}{l}\text { CTG_RP_184.1- } \\
\text { RpL3i-IX-B4 }\end{array}$ & SKI interacting protein & Mus musculus & Q9CV75 & $1.0 \times 10^{-18}$ & 1 \\
\hline $\begin{array}{l}\text { CTG_RP_198.1- } \\
\text { RpL3i-IX-F10 }\end{array}$ & Activin receptor & Xenopus laevis & Q91962 & $1.0 \times 10^{-13}$ & 1 \\
\hline $\begin{array}{l}\text { CTG_RP_258.1- } \\
\text { RpL3i-VI-D8 }\end{array}$ & $\begin{array}{l}\text { COP9 signalosome complex subunit } \\
2\end{array}$ & Drosophila melanogaster & Q94899 & $1.0 \times 10^{-50}$ & 1 \\
\hline $\begin{array}{l}\text { CTG_RP_273.1- } \\
\text { RpL3i-VII-F1 }\end{array}$ & CG2252 protein (RING) & Drosophila melanogaster & Q9W3L3 & $2.0 \times 10^{-30}$ & 1 \\
\hline $\begin{array}{l}\text { CTG_RP_286.1- } \\
\text { RpL3i-VIII-B9 }\end{array}$ & CG7650 protein (phosducin) & Drosophila melanogaster & Q9VUR7 & $2.0 \times 10^{-9}$ & 1 \\
\hline $\begin{array}{l}\text { CTG_RP_289.1- } \\
\text { RpL3i-VIII-D1 }\end{array}$ & Calmodulin & Homo sapiens & Q13942 & $7.0 \times 10^{-22}$ & 1 \\
\hline Metabolism & & & & & 61 \\
\hline $\begin{array}{l}\text { CTG_RP_27.1- } \\
\text { RpL3i-IX-A1 }\end{array}$ & CG9032 protein (ATP synthase) & Drosophila melanogaster & Q9VXN2 & $4.0 \times 10^{-13}$ & 3 \\
\hline $\begin{array}{l}\text { CTG_RP_46.1- } \\
\text { RpL3i-VII-E9 }\end{array}$ & Ubiquitin & Cyanidium caldarium & Q9M3W6 & $1.0 \times 10^{-34}$ & 2 \\
\hline $\begin{array}{l}\text { CTG_RP_47.1- } \\
\text { RpL3i-V-B3 }\end{array}$ & 2-Cys thioredoxin peroxidase & Aedes aegypti & Q8WSF6 & $9.0 \times 10^{-50}$ & 2 \\
\hline $\begin{array}{l}\text { CTG_RP_49.1- } \\
\text { RpL3i-II-D2 }\end{array}$ & Ubiquitin fusion protein & Kluyveromyces lactis & Q9Y854 & $5.0 \times 10^{-27}$ & 2 \\
\hline $\begin{array}{l}\text { CTG_RP_52.1- } \\
\text { RpL3i-V-F1 }\end{array}$ & Putative FK506-binding protein & Suberites domuncula & Q966Y4 & $9.0 \times 10^{-46}$ & 2 \\
\hline $\begin{array}{l}\text { CTG_RP_53.1- } \\
\text { RpL3i-IX-A8 }\end{array}$ & $\mathrm{ADP} / \mathrm{ATP}$ translocase & Anopheles gambiae & Q86PG1 & $1.0 \times 10^{-56}$ & 2 \\
\hline
\end{tabular}


Table 1 (continued)

\begin{tabular}{|c|c|c|c|c|c|}
\hline $\begin{array}{l}\text { Contig name per } \\
\text { category }\end{array}$ & Protein homologue & Species & Accession number & Blast $E$-value & $\begin{array}{l}\text { EST abun- } \\
\text { dance }\end{array}$ \\
\hline $\begin{array}{l}\text { CTG_RP_60.1- } \\
\text { RpL3i-VI-F6 }\end{array}$ & $\begin{array}{l}\text { ATP synthase A chain subunit } 6 \\
\text { (EC 3.6.3.14) }\end{array}$ & Schizaphis graminum & Q9B6H5 & $3.0 \times 10^{-8}$ & 2 \\
\hline $\begin{array}{l}\text { CTG_RP_76.1- } \\
\text { RpL3i-I-A7 }\end{array}$ & hnRNP & Caenorhabditis elegans & Q8WSM6 & $9.0 \times 10^{-7}$ & 1 \\
\hline $\begin{array}{l}\text { CTG_RP_83.1- } \\
\text { RpL3i-I-C1 }\end{array}$ & $\begin{array}{l}\text { CG1490 protein (ubiquitin } \\
\text { protease) }\end{array}$ & Drosophila melanogaster & Q9VYQ8 & $2.0 \times 10^{-20}$ & 1 \\
\hline $\begin{array}{l}\text { CTG_RP_92.1- } \\
\text { RpL3i-I-D2 }\end{array}$ & $\begin{array}{l}\text { CG11015 protein (cytochrome } c \\
\text { oxidase) }\end{array}$ & Drosophila melanogaster & Q9W5N8 & $1.0 \times 10^{-24}$ & 1 \\
\hline $\begin{array}{l}\text { CTG_RP_97.1- } \\
\text { RpL3i-I-E7 }\end{array}$ & Cytochrome oxidase subunit I & Uroleucon ambrosiae & Q9B0T1 & $4.0 \times 10^{-50}$ & 1 \\
\hline $\begin{array}{l}\text { CTG_RP_103.1- } \\
\text { RpL3i-I-F7 }\end{array}$ & Beta-glucosidase precursor & Neotermes koshunensis & Q8T0W7 & $2.0 \times 10^{-12}$ & 1 \\
\hline $\begin{array}{l}\text { CTG_RP_106.1- } \\
\text { RpL3i-I-G11 }\end{array}$ & NACALPHA protein & Drosophila melanogaster & O16813 & $2.0 \times 10^{-33}$ & 1 \\
\hline $\begin{array}{l}\text { CTG_RP_120.1- } \\
\text { RpL3i-II-D4 }\end{array}$ & Cytochrome $c$ oxidase subunit II & Aphis cornifoliae & Q85JS9 & $1.0 \times 10^{-33}$ & 1 \\
\hline $\begin{array}{l}\text { CTG_RP_137.1- } \\
\text { RpL3i-III-C12 }\end{array}$ & Dhm 2 protein $\left(5^{\prime}-3^{\prime}\right.$ exonuclease $)$ & Mus musculus & O35651 & $3.0 \times 10^{-25}$ & 1 \\
\hline $\begin{array}{l}\text { CTG_RP_143.1- } \\
\text { RpL3i-III-E2 }\end{array}$ & $\begin{array}{l}\text { Peptidyl-prolyl cis-trans isomerase } \\
\text { G precursor }\end{array}$ & Tachypleus tridentatus & O44073 & $1.0 \times 10^{-29}$ & 1 \\
\hline $\begin{array}{l}\text { CTG_RP_144.1- } \\
\text { RpL3i-III-F10 }\end{array}$ & $\begin{array}{l}\text { Heterogeneous nuclear } \\
\text { ribonucleoprotein } \mathrm{F}\end{array}$ & Homo sapiens & Q96AU2 & $8.0 \times 10^{-13}$ & 1 \\
\hline $\begin{array}{l}\text { CTG_RP_152.1- } \\
\text { RpL3i-III-G7 }\end{array}$ & hnRNP protein & Chironomus tentans & Q23795 & $5.0 \times 10^{-21}$ & 1 \\
\hline $\begin{array}{l}\text { CTG_RP_155.1- } \\
\text { RpL3i-IV-A6 }\end{array}$ & $\begin{array}{l}\text { CG17397 protein (suppressor of } \\
\text { RNA polymerase B) }\end{array}$ & Drosophila melanogaster & Q9W5P1 & $5.0 \times 10^{-24}$ & 1 \\
\hline $\begin{array}{l}\text { CTG_RP_163.1- } \\
\text { RpL3i-IV-E4 }\end{array}$ & Inorganic pyrophosphatase & Zygosaccharomyces bailii & Q9C0T9 & $4.0 \times 10^{-20}$ & 1 \\
\hline $\begin{array}{l}\text { CTG_RP_164.1- } \\
\text { RpL3i-IV-E5 }\end{array}$ & CNJB protein (DNA binding) & Tetrahymena thermophila & Q94821 & $5.0 \times 10^{-12}$ & 1 \\
\hline $\begin{array}{l}\text { CTG_RP_169.1- } \\
\text { RpL3i-IV-F6 }\end{array}$ & ADP/ATP translocase & Homo sapiens & Q9H0C2 & $6.0 \times 10^{-15}$ & 1 \\
\hline $\begin{array}{l}\text { CTG_RP_173.1- } \\
\text { RpL3i-IV-G7 }\end{array}$ & Ubiquitin fusion protein & Pyrus pyrifolia & Q9LLK2 & $5.0 \times 10^{-26}$ & 1 \\
\hline $\begin{array}{l}\text { CTG_RP_175.1- } \\
\text { RpL3i-IV-G9 }\end{array}$ & Ribonucleotide reductase 2 & Aedes aegypti & Q95VP8 & $3.0 \times 10^{-28}$ & 1 \\
\hline $\begin{array}{l}\text { CTG_RP_182.1- } \\
\text { RpL3i-IX-B11 }\end{array}$ & Ahcy13 protein & Drosophila melanogaster & Q9VXV5 & $1.0 \times 10^{-27}$ & 1 \\
\hline $\begin{array}{l}\text { CTG_RP_185.1- } \\
\text { RpL3i-IX-C1 }\end{array}$ & Elongation factor-2 & Scolopendra polymorpha & Q9BNW7 & $1.0 \times 10^{-33}$ & 1 \\
\hline $\begin{array}{l}\text { CTG_RP_189.1- } \\
\text { RpL3i-IX-D12 }\end{array}$ & Similar to dendritic cell protein & Xenopus laevis & Q7ZYU8 & $5.0 \times 10^{-6}$ & 1 \\
\hline $\begin{array}{l}\text { CTG_RP_191.1- } \\
\text { RpL3i-IX-D4 }\end{array}$ & Nucleoporin 153 & Fugu rubripes & Q9DD34 & $6.0 \times 10^{-7}$ & 1 \\
\hline $\begin{array}{l}\text { CTG_RP_196.1- } \\
\text { RpL3i-IX-E9 }\end{array}$ & Abnormal wing disc-like protein & Choristoneura parallela & Q8MUR5 & $2.0 \times 10^{-14}$ & 1 \\
\hline $\begin{array}{l}\text { CTG_RP_201.1- } \\
\text { RpL3i-IX-F7 }\end{array}$ & Proteasome & Mus musculus & Q8BWT0 & $1.0 \times 10^{-11}$ & 1 \\
\hline $\begin{array}{l}\text { CTG_RP_213.1- } \\
\text { RpL3i-V-A1 }\end{array}$ & Aldehyde dehydrogenase & Drosophila melanogaster & O46056 & $3.0 \times 10^{-22}$ & 1 \\
\hline $\begin{array}{l}\text { CTG_RP_217.1- } \\
\text { RpL3i-V-B4 }\end{array}$ & $\begin{array}{l}\text { CG3174 protein (flavon-containing } \\
\text { monooxygenase) }\end{array}$ & Drosophila melanogaster & Q9V9C9 & $3.0 \times 10^{-26}$ & 1 \\
\hline $\begin{array}{l}\text { CTG_RP_218.1- } \\
\text { RpL3i-V-B7 }\end{array}$ & $\begin{array}{l}\text { Phosphoribosylaminoimidazole } \\
\text { carboxylase }\end{array}$ & Danio rerio & Q7ZUN6 & $2.0 \times 10^{-38}$ & 1 \\
\hline $\begin{array}{l}\text { CTG_RP_226.1- } \\
\text { RpL3i-V-D8 }\end{array}$ & Translation initiation factor 3 & Drosophila melanogaster & Q8MR84 & $4.0 \times 10^{-07}$ & 1 \\
\hline $\begin{array}{l}\text { CTG_RP_229.1- } \\
\text { RpL3i-V-F2 }\end{array}$ & CG14214 protein (SEC 61) & Drosophila melanogaster & Q9VWE9 & $9.0 \times 10^{-21}$ & 1 \\
\hline $\begin{array}{l}\text { CTG_RP_234.1- } \\
\text { RpL3i-V-H5 }\end{array}$ & ATP synthase c-subunit & Dermacentor variabilis & Q86G68 & $5.0 \times 10^{-22}$ & 1 \\
\hline $\begin{array}{l}\text { CTG_RP_236.1- } \\
\text { RpL3i-V-H9 }\end{array}$ & UDP-glucuronosyltransferase $1 \mathrm{~A} 7$ & Rattus norvegicus & Q8VD43 & $6.0 \times 10^{-24}$ & 1 \\
\hline
\end{tabular}


Table 1 (continued)

\begin{tabular}{|c|c|c|c|c|c|}
\hline $\begin{array}{l}\text { Contig name per } \\
\text { category }\end{array}$ & Protein homologue & Species & Accession number & Blast $E$-value & $\begin{array}{l}\text { EST abun- } \\
\text { dance }\end{array}$ \\
\hline $\begin{array}{l}\text { CTG_RP_247.1- } \\
\text { RpL3i-VI-B9 }\end{array}$ & Glutamine synthetase & Biomphalaria glabrata & Q8IS07 & $1.0 \times 10^{-27}$ & 1 \\
\hline $\begin{array}{l}\text { CTG_RP_254.1- } \\
\text { RpL3i-VI-D10 }\end{array}$ & $\begin{array}{l}\text { CG6105 protein (ATP synthase } \gamma \\
\text { subunit }\end{array}$ & Drosophila melanogaster & Q9VKM3 & $5.0 \times 10^{-22}$ & 1 \\
\hline $\begin{array}{l}\text { CTG_RP_255.1- } \\
\text { RpL3i-VI-D11 }\end{array}$ & $\begin{array}{l}\text { GH21728p (translation initiation } \\
\text { factor 3) }\end{array}$ & Drosophila melanogaster & Q8MR49 & $2.0 \times 10^{-41}$ & 1 \\
\hline $\begin{array}{l}\text { CTG_RP_274.1- } \\
\text { RpL3i-VII-G4 }\end{array}$ & Proliferating cell nuclear antigen & Hyphantria cunea & Q8MYA4 & $3.0 \times 10^{-29}$ & 1 \\
\hline $\begin{array}{l}\text { CTG_RP_285.1- } \\
\text { RpL3i-VIII-B7 }\end{array}$ & Acyl-CoA delta-11 desaturase & Heliothis zea & Q9NB26 & $1.0 \times 10^{-10}$ & 1 \\
\hline $\begin{array}{l}\text { CTG_RP_287.1- } \\
\text { RpL3i-VIII-C11 }\end{array}$ & $\begin{array}{l}\text { CG5384 protein (tRNA guanine } \\
\text { transglycosylase) }\end{array}$ & Drosophila melanogaster & Q9VKZ8 & $1.0 \times 10^{-29}$ & 1 \\
\hline $\begin{array}{l}\text { CTG_RP_294.1- } \\
\text { RpL3i-VIII-E2 }\end{array}$ & dUTPase & Mus musculus & Q9CQ43 & $2.0 \times 10^{-24}$ & 1 \\
\hline $\begin{array}{l}\text { CTG_RP_307.1- } \\
\text { RpL3i-X-A4 }\end{array}$ & $\begin{array}{l}\text { SD19419p (uroporphyrinogen } \\
\text { decarboxylase) }\end{array}$ & Drosophila melanogaster & Q8MRV9 & $2.0 \times 10^{-14}$ & 1 \\
\hline $\begin{array}{l}\text { CTG_RP_312.1- } \\
\text { RpL3i-X-B5 }\end{array}$ & $\begin{array}{l}\text { Glyceraldehyde 3-phosphate } \\
\text { dehydrogenase }\end{array}$ & Drosophila melanogaster & Q8SXG8 & $1.0 \times 10^{-10}$ & 1 \\
\hline $\begin{array}{l}\text { CTG_RP_323.1- } \\
\text { RpL3i-X-F7 }\end{array}$ & LD32039p (DNA binding protein) & Drosophila melanogaster & Q8MZ43 & $6.0 \times 10^{-37}$ & 1 \\
\hline $\begin{array}{l}\text { CTG_RP_329.1- } \\
\text { RpL3i-XI-A11 }\end{array}$ & Putative Eip71CD protein & Drosophila melanogaster & Q9VUP4 & $3.0 \times 10^{-14}$ & 1 \\
\hline $\begin{array}{l}\text { CTG_RP_336.1- } \\
\text { RpL3i-XI-B9 }\end{array}$ & Pyruvate carboxylase & Aedes aegypti & Q16921 & $1.0 \times 10^{-23}$ & 1 \\
\hline $\begin{array}{l}\text { CTG_RP_343.1- } \\
\text { RpL3i-XI-D8 }\end{array}$ & $\begin{array}{l}\text { CG7006 protein (ribosome } \\
\text { biogenesis) }\end{array}$ & Drosophila melanogaster & Q9VC28 & $1.0 \times 10^{-18}$ & 1 \\
\hline $\begin{array}{l}\text { CTG_RP_346.1- } \\
\text { RpL3i-XI-E5 }\end{array}$ & H+-ATPase subunit & Sus scrofa & Q9T2U6 & $2.0 \times 10^{-9}$ & 1 \\
\hline $\begin{array}{l}\text { CTG_RP_355.1- } \\
\text { RpL3i-XI-G7 }\end{array}$ & Cytochrome $b$ & Siphateles bicolor & Q85U34 & $2.0 \times 10^{-12}$ & 1 \\
\hline $\begin{array}{l}\text { CTG_RP_356.1- } \\
\text { RpL3i-XI-G8 }\end{array}$ & SMT3 protein & Drosophila melanogaster & O97102 & $3.0 \times 10^{-15}$ & 1 \\
\hline Ribosomal proteins & & & & & 122 \\
\hline $\begin{array}{l}\text { CTG_RP_4.1- } \\
\text { RpL3i-I-E4 }\end{array}$ & Ribosomal protein $\mathrm{L} 17 / 23$ & Spodoptera frugiperda & Q962Y9 & $2.0 \times 10^{-63}$ & 5 \\
\hline $\begin{array}{l}\text { CTG_RP_5.1- } \\
\text { RpL3i-I-D1 }\end{array}$ & Ribosomal protein $\mathrm{P} 2$ & Ceratitis capitata & O96934 & $8.0 \times 10^{-16}$ & 5 \\
\hline $\begin{array}{l}\text { CTG_RP_6.1- } \\
\text { RpL3i-I-H1 }\end{array}$ & RE05022p (Ribosomal protein L71) & Drosophila melanogaster & Q9W3Z2 & $2.0 \times 10^{-34}$ & 5 \\
\hline $\begin{array}{l}\text { CTG_RP_7.1- } \\
\text { RpL3i-III-D5 }\end{array}$ & Ribosomal protein L26 & Spodoptera frugiperda & Q962T4 & $3.0 \times 10^{-54}$ & 5 \\
\hline $\begin{array}{l}\text { CTG_RP_8.1- } \\
\text { RpL3i-III-C1 }\end{array}$ & $\begin{array}{l}\text { QM protein (Ribosomal protein } \\
\text { L10) }\end{array}$ & Heliothis virescens & Q95PD4 & $2.0 \times 10^{-72}$ & 5 \\
\hline $\begin{array}{l}\text { CTG_RP_9.1- } \\
\text { RpL3i-I-E6 }\end{array}$ & $\begin{array}{l}\text { CG7424 protein (Ribosomal } \\
\text { protein L44) }\end{array}$ & Drosophila melanogaster & Q9VLT7 & $8.0 \times 10^{-40}$ & 5 \\
\hline $\begin{array}{l}\text { CTG_RP_12.1- } \\
\text { RpL3i-III-B1 }\end{array}$ & Ribosomal protein $\mathrm{S} 9$ & Drosophila melanogaster & Q9VT06 & $1.0 \times 10^{-78}$ & 4 \\
\hline $\begin{array}{l}\text { CTG_RP_14.1- } \\
\text { RpL3i-I-C4 }\end{array}$ & Ribosomal protein L14 & Spodoptera frugiperda & Q962T9 & $1.0 \times 10^{-34}$ & 4 \\
\hline $\begin{array}{l}\text { CTG_RP_16.1- } \\
\text { RpL3i-II-B8 }\end{array}$ & Ribosomal protein L34 & Spodoptera frugiperda & Q8WQI6 & $3.0 \times 10^{-41}$ & 4 \\
\hline $\begin{array}{l}\text { CTG_RP_17.1- } \\
\text { RpL3i-III-G10 }\end{array}$ & $\begin{array}{l}\text { CG7283 protein (ribosomal protein } \\
\text { L10A) }\end{array}$ & Drosophila melanogaster & Q9VTP4 & $5.0 \times 10^{-63}$ & 4 \\
\hline $\begin{array}{l}\text { CTG_RP_20.1- } \\
\text { RpL3i-IV-D9 }\end{array}$ & $\begin{array}{l}\text { CG5827 protein (ribosomal } \\
\text { protein) }\end{array}$ & Drosophila melanogaster & Q9VMU4 & $1.0 \times 10^{-31}$ & 3 \\
\hline $\begin{array}{l}\text { CTG_RP_21.1- } \\
\text { RpL3i-I-A11 }\end{array}$ & Similar to ribosomal protein $\mathrm{S} 8$ & Bos taurus & Q862P8 & $1.0 \times 10^{-47}$ & 3 \\
\hline $\begin{array}{l}\text { CTG_RP_22.1- } \\
\text { RpL3i-IX-F2 }\end{array}$ & Ribosomal protein $\mathrm{S} 21$ & Spodoptera frugiperda & Q962Q8 & $1.0 \times 10^{-28}$ & 3 \\
\hline
\end{tabular}


Table 1 (continued)

\begin{tabular}{|c|c|c|c|c|c|}
\hline $\begin{array}{l}\text { Contig name per } \\
\text { category }\end{array}$ & Protein homologue & Species & Accession number & Blast $E$-value & $\begin{array}{l}\text { EST abun- } \\
\text { dance }\end{array}$ \\
\hline $\begin{array}{l}\text { CTG_RP_24.1- } \\
\text { RpL3i-II-E12 }\end{array}$ & Ribosomal protein L8 & Spodoptera frugiperda & Q95V39 & $2.0 \times 10^{-75}$ & 3 \\
\hline $\begin{array}{l}\text { CTG_RP_25.1- } \\
\text { RpL3i-IV-F7 }\end{array}$ & Ribosomal protein L18 & Branchiostoma lanceolatum & Q86LX2 & $3.0 \times 10^{-42}$ & 3 \\
\hline $\begin{array}{l}\text { CTG_RP_29.1- } \\
\text { RpL3i-III-D2 }\end{array}$ & Ribosomal protein S23 & Spodoptera frugiperda & Q962Q7 & $6.0 \times 10^{-50}$ & 3 \\
\hline $\begin{array}{l}\text { CTG_RP_30.1- } \\
\text { RpL3i-I-D5 }\end{array}$ & $\begin{array}{l}\text { CG2998 protein (ribosomal protein } \\
\text { S28) }\end{array}$ & Drosophila melanogaster & Q9W334 & $1.0 \times 10^{-20}$ & 3 \\
\hline $\begin{array}{l}\text { CTG_RP_31.1- } \\
\text { RpL3i-III-D12 }\end{array}$ & Ribosomal protein L29 & Spodoptera frugiperda & Q95V37 & $6.0 \times 10^{-18}$ & 3 \\
\hline $\begin{array}{l}\text { CTG_RP_34.1- } \\
\text { RpL3i-IV-B10 }\end{array}$ & Ribosomal protein S3 & Spodoptera frugiperda & Q95V36 & $1.0 \times 10^{-77}$ & 3 \\
\hline $\begin{array}{l}\text { CTG_RP_36.1- } \\
\text { RpL3i-III-C11 }\end{array}$ & Ribosomal protein L11 & Petromyzon marinus & Q801H8 & $7.0 \times 10^{-24}$ & 3 \\
\hline $\begin{array}{l}\text { CTG_RP_45.1- } \\
\text { RpL3i-IV-A12 }\end{array}$ & $60 \mathrm{~S}$ ribosomal protein L15 & Spodoptera frugiperda & Q8I9V9 & $5.0 \times 10^{-43}$ & 2 \\
\hline $\begin{array}{l}\text { CTG_RP_54.1- } \\
\text { RpL3i-II-E5 }\end{array}$ & Ribosomal protein L30 & Aequipecten irradians & Q8ITC5 & $2.0 \times 10^{-12}$ & 2 \\
\hline $\begin{array}{l}\text { CTG_RP_55.1- } \\
\text { RpL3i-II-A9 }\end{array}$ & Ribosomal protein L35A & Spodoptera frugiperda & Q962S9 & $1.0 \times 10^{-36}$ & 2 \\
\hline $\begin{array}{l}\text { CTG_RP_57.1- } \\
\text { RpL3i-III-B3 }\end{array}$ & Ribosomal protein L32 & Spodoptera frugiperda & Q962T1 & $5.0 \times 10^{-58}$ & 2 \\
\hline $\begin{array}{l}\text { CTG_RP_58.1- } \\
\text { RpL3i-I-B12 }\end{array}$ & Ribosomal protein S15 & Spodoptera frugiperda & Q962R4 & $7.0 \times 10^{-50}$ & 2 \\
\hline $\begin{array}{l}\text { CTG_RP_63.1- } \\
\text { RpL3i-I-F1 }\end{array}$ & RpS4 protein & Drosophila melanogaster & Q9VU44 & $4.0 \times 10^{-30}$ & 2 \\
\hline $\begin{array}{l}\text { CTG_RP_67.1- } \\
\text { RpL3i-I-E12 }\end{array}$ & $\begin{array}{l}\text { CG3751 protein (ribosomal protein } \\
\text { S24) }\end{array}$ & Drosophila melanogaster & Q9W229 & $3.0 \times 10^{-33}$ & 2 \\
\hline $\begin{array}{l}\text { CTG_RP_68.1- } \\
\text { RpL3i-I-E1 }\end{array}$ & Ribosomal protein L36A & Spodoptera frugiperda & Q962S8 & $5.0 \times 10^{-28}$ & 2 \\
\hline $\begin{array}{l}\text { CTG_RP_70.1- } \\
\text { RpL3i-III-C7 }\end{array}$ & Ribosomal protein S26 & Spodoptera frugiperda & Q962Q4 & $1.0 \times 10^{-50}$ & 2 \\
\hline $\begin{array}{l}\text { CTG_RP_77.1- } \\
\text { RpL3i-I-A8 }\end{array}$ & Ribosomal protein S16 & Spodoptera frugiperda & Q95V31 & $3.0 \times 10^{-26}$ & 1 \\
\hline $\begin{array}{l}\text { CTG_RP_78.1- } \\
\text { RpL3i-I-A9 }\end{array}$ & Ribosomal protein $\mathrm{P} 0$ & Aedes albopictus & Q8MQT0 & $2.0 \times 10^{-45}$ & 1 \\
\hline $\begin{array}{l}\text { CTG_RP_79.1- } \\
\text { RpL3i-I-B3 }\end{array}$ & Ribosomal protein S19 & Spodoptera frugiperda & Q962R0 & $3.0 \times 10^{-42}$ & 1 \\
\hline $\begin{array}{l}\text { CTG_RP_80.1- } \\
\text { RpL3i-I-B5 }\end{array}$ & Similar to ribosomal protein & Xenopus laevis & Q7ZYR6 & $5.0 \times 10^{-52}$ & 1 \\
\hline $\begin{array}{l}\text { CTG_RP_85.1- } \\
\text { RpL3i-I-C3 }\end{array}$ & Ribosomal protein L13 & Xenopus laevis & Q8AVQ1 & $4.0 \times 10^{-15}$ & 1 \\
\hline $\begin{array}{l}\text { CTG_RP_96.1- } \\
\text { RpL3i-I-E5 }\end{array}$ & Ribosomal protein S10 & Branchiostoma belcheri & Q86QR8 & $2.0 \times 10^{-41}$ & 1 \\
\hline $\begin{array}{l}\text { CTG_RP_111.1- } \\
\text { RpL3i-II-A2 }\end{array}$ & RE28824p (ribosomal protein L12) & Drosophila melanogaster & Q9W1B9 & $5.0 \times 10^{-38}$ & 1 \\
\hline $\begin{array}{l}\text { CTG_RP_121.1- } \\
\text { RpL3i-II-E2 }\end{array}$ & Ribosomal protein S18 & Branchiostoma belcheri & Q8ISP0 & $3.0 \times 10^{-9}$ & 1 \\
\hline $\begin{array}{l}\text { CTG_RP_150.1- } \\
\text { RpL3i-III-G12 }\end{array}$ & Ribosomal protein S26 & Spodoptera frugiperda & Q962Q4 & $3.0 \times 10^{-6}$ & 1 \\
\hline $\begin{array}{l}\text { CTG_RP_153.1- } \\
\text { RpL3i-IV-A3 }\end{array}$ & Ribosomal protein S5 & Spodoptera frugiperda & Q95V33 & $7.0 \times 10^{-34}$ & 1 \\
\hline $\begin{array}{l}\text { CTG_RP_156.1- } \\
\text { RpL3i-IV-A9 }\end{array}$ & Ribosomal protein L18a & Xenopus laevis & Q7ZYQ8 & $2.0 \times 10^{-42}$ & 1 \\
\hline $\begin{array}{l}\text { CTG_RP_158.1- } \\
\text { RpL3i-IV-B9 }\end{array}$ & $\begin{array}{l}\text { CG12740 protein (ribosomal } \\
\text { protein L28) }\end{array}$ & Drosophila melanogaster & Q9VZS4 & $3.0 \times 10^{-16}$ & 1 \\
\hline $\begin{array}{l}\text { CTG_RP_165.1- } \\
\text { RpL3i-IV-E7 }\end{array}$ & Ribosomal protein S19 & Aequipecten irradians & Q8ITC3 & $3.0 \times 10^{-14}$ & 1 \\
\hline $\begin{array}{l}\text { CTG_RP_176.1- } \\
\text { RpL3i-IV-H2 }\end{array}$ & Ribosomal protein S6 & Mus musculus & Q8BT09 & $2.0 \times 10^{-28}$ & 1 \\
\hline $\begin{array}{l}\text { CTG_RP_178.1- } \\
\text { RpL3i-IV-H8 }\end{array}$ & Ribosomal protein L38 & Spodoptera frugiperda & Q962S5 & $2.0 \times 10^{-22}$ & 1 \\
\hline
\end{tabular}


Table 1 (continued)

\begin{tabular}{|c|c|c|c|c|c|}
\hline $\begin{array}{l}\text { Contig name per } \\
\text { category }\end{array}$ & Protein homologue & Species & Accession number & Blast $E$-value & $\begin{array}{l}\text { EST abun- } \\
\text { dance }\end{array}$ \\
\hline $\begin{array}{l}\text { CTG_RP_197.1- } \\
\text { RpL3i-IX-F1 }\end{array}$ & Similar to ribosomal protein L17 & Xenopus laevis & Q7ZY53 & $2.0 \times 10^{-22}$ & 1 \\
\hline $\begin{array}{l}\text { CTG_RP_237.1- } \\
\text { RpL3i-VI-A10 }\end{array}$ & 60 S ribosomal protein $\mathrm{L} 27$ & Drosophila melanogaster & Q9VBN5 & $2.0 \times 10^{-54}$ & 1 \\
\hline $\begin{array}{l}\text { CTG_RP_240.1- } \\
\text { RpL3i-VI-A6 }\end{array}$ & $\begin{array}{l}\text { CG4046 protein (ribosomal protein } \\
\text { S16) }\end{array}$ & Drosophila melanogaster & Q9W237 & $4.0 \times 10^{-37}$ & 1 \\
\hline $\begin{array}{l}\text { CTG_RP_252.1- } \\
\text { RpL3i-VI-C7 }\end{array}$ & Ribosomal protein L44 & Chlamys farreri & Q8MUE4 & $8.0 \times 10^{-14}$ & 1 \\
\hline $\begin{array}{l}\text { CTG_RP_260.1- } \\
\text { RpL3i-VI-F10 }\end{array}$ & Ribosomal protein L7Ae-like & Mus musculus & Q9D0T1 & $4.0 \times 10^{-39}$ & 1 \\
\hline $\begin{array}{l}\text { CTG_RP_278.1- } \\
\text { RpL3i-VII-H10 }\end{array}$ & Ribosomal protein S15A & Spodoptera frugiperda & Q962R3 & $2.0 \times 10^{-26}$ & 1 \\
\hline $\begin{array}{l}\text { CTG_RP_281.1- } \\
\text { RpL3i-VII-H5 }\end{array}$ & Ribosomal protein L19 & Ictalurus punctatus & Q90YU8 & $9.0 \times 10^{-27}$ & 1 \\
\hline $\begin{array}{l}\text { CTG_RP_304.1- } \\
\text { RpL3i-VIII-H7 }\end{array}$ & Ribosomal protein L31 & Heliothis virescens & Q9GP16 & $3.0 \times 10^{-19}$ & 1 \\
\hline $\begin{array}{l}\text { CTG_RP_320.1- } \\
\text { RpL3i-X-E8 }\end{array}$ & Ribosomal protein L9 & Branchiostoma belcheri & Q8ISP7 & $2.0 \times 10^{-24}$ & 1 \\
\hline $\begin{array}{l}\text { CTG_RP_313.1- } \\
\text { RpL3i-X-B9 }\end{array}$ & $60 \mathrm{~S}$ acidic ribosomal protein $\mathrm{P} 0$ & Spodoptera frugiperda & Q8WQJ2 & $4.0 \times 10^{-40}$ & 1 \\
\hline $\begin{array}{l}\text { CTG_RP_327.1- } \\
\text { RpL3i-X-H12 }\end{array}$ & Ribosomal protein S11 & Heliothis virescens & Q95P67 & $3.0 \times 10^{-30}$ & 1 \\
\hline $\begin{array}{l}\text { CTG_RP_328.1- } \\
\text { RpL3i-X-H5 }\end{array}$ & Ribosomal protein $\mathrm{S} 18$ & Spodoptera frugiperda & Q962R1 & $3.0 \times 10^{-21}$ & 1 \\
\hline $\begin{array}{l}\text { CTG_RP_330.1- } \\
\text { RpL3i-XI-A2 }\end{array}$ & Ribosomal protein $\mathrm{S} 18$ & Spodoptera frugiperda & Q962R1 & $2.0 \times 10^{-28}$ & 1 \\
\hline Structure & & & & & 27 \\
\hline $\begin{array}{l}\text { CTG_RP_3.1- } \\
\text { RpL3i-II-B12 }\end{array}$ & Histone $\mathrm{H} 1$ & Rhynchosciara americana & Q963G2 & $3.0 \times 10^{-20}$ & 6 \\
\hline $\begin{array}{l}\text { CTG_RP_19.1- } \\
\text { RpL3i-I-F9 }\end{array}$ & Alpha-4-tubulin & Gecarcinus lateralis & O01944 & $4.0 \times 10^{-95}$ & 3 \\
\hline $\begin{array}{l}\text { CTG_RP_33.1- } \\
\text { RpL3i-II-H3 }\end{array}$ & Troponin $\mathrm{T}$ & Periplaneta americana & Q9XZ71 & $7.0 \times 10^{-6}$ & 3 \\
\hline $\begin{array}{l}\text { CTG_RP_51.1- } \\
\text { RpL3i-V-B9 }\end{array}$ & Troponin I-like protein & Haemaphysalis longicornis & Q969A1 & $9.0 \times 10^{-21}$ & 2 \\
\hline $\begin{array}{l}\text { CTG_RP_86.1- } \\
\text { RpL3i-I-C5 }\end{array}$ & Actin 1 & Culicoides sonorensis & Q8WRE6 & $8.0 \times 10^{-83}$ & 1 \\
\hline $\begin{array}{l}\text { CTG_RP_88.1- } \\
\text { RpL3i-I-C7 }\end{array}$ & RH04334p (Articulin) & Drosophila melanogaster & Q8SZM2 & $8.0 \times 10^{-17}$ & 1 \\
\hline $\begin{array}{l}\text { CTG_RP_94.1- } \\
\text { RpL3i-I-D7 }\end{array}$ & DNM1 protein (dynamin) & Homo sapiens & Q86VD2 & $3.0 \times 10^{-36}$ & 1 \\
\hline $\begin{array}{l}\text { CTG_RP_105.1- } \\
\text { RpL3i-I-G10 }\end{array}$ & Putative cytoskeletal actin & Ciona intestinalis & Q8I7E1 & $2.0 \times 10^{-51}$ & 1 \\
\hline $\begin{array}{l}\text { CTG_RP_115.1- } \\
\text { RpL3i-II-B6 }\end{array}$ & Putative HMG-like protein & Dermacentor variabilis & Q86G70 & $8.0 \times 10^{-15}$ & 1 \\
\hline $\begin{array}{l}\text { CTG_RP_136.1- } \\
\text { RpL3i-III-B9 }\end{array}$ & RE12057p (actin) & Drosophila melanogaster & Q8MZ23 & $5.0 \times 10^{-27}$ & 1 \\
\hline $\begin{array}{l}\text { CTG_RP_145.1- } \\
\text { RpL3i-III-F2 }\end{array}$ & $\begin{array}{l}\text { CG11274 (serine/arginine repetitive } \\
\text { matrix } 1 \text { protein) }\end{array}$ & Drosophila melanogaster & Q9VU43 & $5.0 \times 10^{-43}$ & 1 \\
\hline $\begin{array}{l}\text { CTG_RP_199.1- } \\
\text { RpL3i-IX-F11 }\end{array}$ & Histone $\mathrm{H} 1$ & Tigriopus californicus & P92139 & $2.0 \times 10^{-8}$ & 1 \\
\hline $\begin{array}{l}\text { CTG_RP_221.1- } \\
\text { RpL3i-V-C8 }\end{array}$ & Alpha-tubulin & Spirometra erinaceieuropaei & Q9NL73 & $2.0 \times 10^{-53}$ & 1 \\
\hline $\begin{array}{l}\text { CTG_RP_228.1- } \\
\text { RpL3i-V-F12 }\end{array}$ & Histone $\mathrm{H} 2$ & Arabidopsis thaliana & Q8GUH3 & $1.0 \times 10^{-33}$ & 1 \\
\hline $\begin{array}{l}\text { CTG_RP_279.1- } \\
\text { RpL3i-VII-H3 }\end{array}$ & Actin & Aplysia californica & Q16942 & $2.0 \times 10^{-18}$ & 1 \\
\hline $\begin{array}{l}\text { CTG_RP_309.1- } \\
\text { RpL3i-X-A9 }\end{array}$ & Actin 1 & Culicoides sonorensis & Q8WRE6 & $6.0 \times 10^{-59}$ & 1 \\
\hline $\begin{array}{l}\text { CTG_RP_319.1- } \\
\text { RpL3i-X-D5 }\end{array}$ & Tropomyosin & Lepisma saccharina & Q8T379 & $8.0 \times 10^{-24}$ & 1 \\
\hline
\end{tabular}


with $T$. citricida contigs. This contig version is no further analysed in order to eliminate the risk of working on in silico-defined chimeric sequences from different aphid species.

After annotation, contigs from the " $R$. padi contig" were grouped into functional categories (Table 1). Gene Ontology annotation was also performed (Table 2) showing a high representation for "physiological process", "cell", "binding" and "catalytic activity" terms.

A cellular role could be assigned for $44 \%$ of the $R$. padi contigs (Table 1 ) on the basis of sequence similarity to proteins with known function in public databases using BLAstX with an $E$-value $\leq 10^{-5}$. The remaining $56 \%$ fall into the "hypothetical" $(6 \%)$ or "no hit" $(50 \%)$ categories (Fig. 2) and the most abundant sequence (CTG_RP_1.1-RpL3i-I-D6 harbouring 13 ESTs) belongs to the "no hit" category. This proportion is similar to that observed for other insect EST projects as for $S$. frugiperda (Landais et al., 2003), B. mori (Mita et al., 2003) or T. citricida (Hunter et al., 2003). The most likely reason for this lack of similarity is that some of these sequences are probably too short or may be constituted by $5^{\prime}$ - or $3^{\prime}$-unstranslated regions. A second possibility is that these partial sequences correspond to non-conserved domains of polypeptides: a longer sequence should allow a better

Table 2

Gene Ontology annotation of the $R$. padi contig

\begin{tabular}{ll}
\hline Gene Ontology & Number (\%) of contigs \\
\hline Biological process & $72(100)$ \\
Behavior & $0(0)$ \\
Unknown & $7(9.7)$ \\
Cellular process & $25(34.7)$ \\
Development & $13(18.0)$ \\
Physiological process & $27(37.5)$ \\
Cellular component & $37(100)$ \\
Cell & $27(73)$ \\
Unknown & $10(27)$ \\
Extracellular & $0(0)$ \\
Unlocalized & $0(0)$ \\
Molecular function & $50(100)$ \\
Antioxydant activity & $0(0)$ \\
Apoptosis regulator activity & $0(0)$ \\
Binding & $14(28)$ \\
Catalytic activity & $13(26)$ \\
Cell adhesion molecule activity & $0(0)$ \\
Chaperone activity & $3(6)$ \\
Defense/immunity protein activity & $0(0)$ \\
Enzyme regulator activity & $0(0)$ \\
Unknown & $3(6)$ \\
Motor activity & $0(0)$ \\
Protein tagging activity & $1(2)$ \\
Signal transducer activity & $5(10)$ \\
Structural molecule activity & $1(2)$ \\
Transcription regulator activity & $2(4)$ \\
Translation regulator activity & $0(0)$ \\
Transporter activity & $8(16)$ \\
\hline
\end{tabular}

identification of these ESTs. Finally, some of these proteins with unknown functions might correspond to aphid specific cellular functions not yet elucidated. Domazet-Loso and Tautz (2003) proposed that genes involved in environmental adaptation evolve quickly and might correspond to orphan sequences. As aphids are highly sensitive to environmental changes, it could be that many of these orphan genes correspond to sequences rapidly evolving. The largest proportion of functionally assigned sequences fall into three functional categories: metabolism $(16 \%)$, ribosomal proteins $(17 \%)$, and structure $(5 \%)$. Of note is the presence of chaperonins $(2 \%)$ as well as a high representation (38\%) of house keeping genes involved in general cellular functions (categories 1, 2 and 3). The large proportion of housekeeping genes is lower than the one found for $S$. frugiperda EST collection which was constructed from cultured cells (Landais et al., 2003): the function of these cultured cells - even if they originated from ovarian cells - are likely to have most of their highly expressed genes directed mainly towards general metabolism, gene expression and cell division. The high proportion of housekeeping genes in our collection probably results from the use of whole-insects for preparing the cDNA library. Housekeeping genes being ubiquitously expressed within cells, their predominance may reduce the chance to identify other genes expressed within a narrow range of cells and/or following a specific challenge. A large number of the housekeeping $R$. padi ESTs belongs to the ribosomal protein gene family (34\% of the housekeeping proteins and $17 \%$ of total ESTs) directly involved in mRNA translation and protein synthesis. The number (57 clusters, Table 1) of the different ribosomal proteins found in our collection might represent a large proportion of the 80 predictive ribosomal protein complement (Landais et al., 2003). These genes are known to be highly expressed and present in most cell types.

Some genes $(4 \%)$ involved in specific developmental events were identified. Full length sequences were obtained for three of these inserts: pelota, bgcn and exuperantia because there are all involved in early steps of oocyte differentiation or embryo development in Drosophila (see below). None of these inserts corresponded to full length cDNA sequences. R. padi bgcn, pelota and exuperantia deduced amino acids sequences showed a high similarity to Drosophila orthologous (76\%, 89\% and $47 \%$, respectively) as well as to vertebrate sequences (except for exuperantia) (Fig. 3). During aphid parthenogenesis, in contrast with sexual differentiation, oocytes are arrested in the first meiotic division and undergo embryogenesis at a $2 n$ stage without fertilization by spermatozoids (Blackman, 1987). Very little is known about the molecular events involved in this process, but the regulation of the meiotic cycle is probably a key step before the bifurcation 


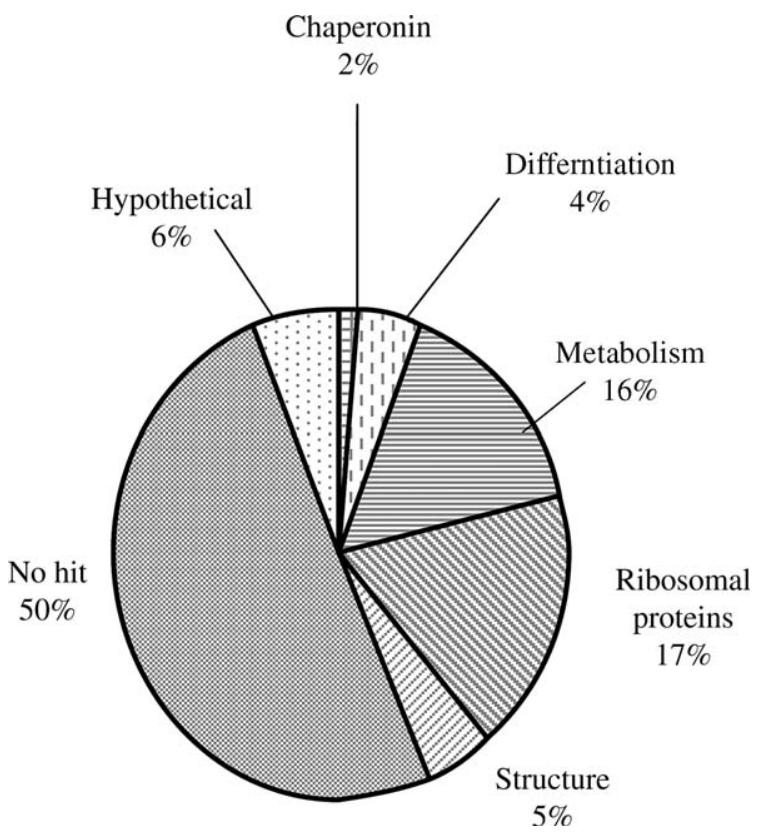

Fig. 2. Distribution by functional categories of 361 transcripts forming the " $R$. padi contig".

towards the two developmental orientations. The pelota-related gene (CTG_RP_122.1-RpL3i-II-F11) was identified that may regulate early divisions of aphid oocytes since in Drosophila mutations in pelota genes not only caused defects in spermatogenesis but also affected mitotic divisions during the development of ovaries (Adham et al., 2003). Contig CTG_RP_75.1RpL3i-I-A2 was similar to a cystoblast differentiation factor (begnin gonial cell neoplasm) of Drosophila melanogaster. This gene is involved in the regulation of the asymmetric division of germline stem cells giving the cystoblast from which oocytes will later differentiate (Ohlstein et al., 2000). The exuperantia gene (CTG_RP_147.1-RpL3i-III-F4) is involved in the prelocalization of a small set of maternally expressed genes in D. melanogaster embryos (Macdonald et al., 1991). The presence of these two later genes in $R$. padi suggests regulation mechanisms for oocyte and embryos development involving syncytial structure and mRNA localization. It is noteworthy that we did not find in our EST catalog the ApSDI-1 gene described by Ramos et al. (2003): it encodes an amino-acid transporter in neurons and is expressed in short-days reared pea aphids (Acyrthosiphon pisum). This gene is probably lowly expressed and a substractive approach was necessary to identify it in $A$. pisum.

In order to more precisely describe the abundant "no hit" sequences of the " $R$. padi contig", we performed a BLASTX comparison on the orphan contigs with the filter off, to eventually detect sequences of low complexity which might have been lost in the original filtered BlastX. Additional $(n=23)$ contigs were found to have similarity to known polypeptides (Table 3) which are rich however in repeat domains.

A Student test comparing the mean length of the 189 sequences showing a hit with the not hit 172 sequences indicated that no hit sequences were smaller (risk $\alpha$ of $1 \times 10^{-32}$ ). GC contents were also compared between sequences with and without a hit: no hit sequences were richer in GC than sequences showing a hit $\left(p<0.001, \chi^{2}\right.$ test), indicating the probable presence of non-translated regions. The high GC content observed for sequences having no hit can also be an indicator of either a $5^{\prime}$-untranslated region or a non-protein coding RNA. Post-genomic approaches should help in understanding the role of these proteins in aphid biology.

Codon bias was often detected in Drosophila genes. We analysed by gene categories (as defined in Table 1) the codon usage of the $R$. padi sequences having a hit. A $\chi^{2}$ test showed that all protein categories except the "metabolism" class have a codon usage significantly different from the average codon usage (i.e. pooling all the sequences from all categories). A codon usage bias has been described in $D$. melanogaster for ribosomal proteins. Our preliminary analysis also indicated a codon usage bias for ribosomal proteins of $R$. padi. However, our collection of total $R$. padi sequences is still limited for that kind of studies as it contains no full-lengths sequences. Furthermore, the cDNA clones of $R$. padi were randomly picked from the library clones and probably corresponded (because of their small quantity: 1056) mainly to highly expressed genes; our sample is thus probably biased. A larger collection of ESTs and a precise analysis gene by gene (including a comparison with orthologs from other insects) will be necessary to show whether some aphid genes present significant codon usage bias.

EST sequences can be a source of molecular markers particularly for microsatellites sequences. At least two microsatellite motifs have been detected in CTG_RP_28.1-RpL3i-III-G9 and CTG_RP_194.1RpL3i-IX-E4, corresponding to (TGG) 9 and (TTA)7 repeats, respectively (Fig. 4). One small and one imperfect repeats were also detected in CTG_RP_ 146.1-RpL3i-III-F3 [(TTA)4] and CTG_RP_261.1RpL3i-XI-F3 [(TGG)3 found twice separated by 77 bases], respectively (Fig. 4). Three microsatellite repeats (CTG_RP_28.1-RpL3i-III-G9, CTG_RP_194.1-RpL3iIX-E4, CTG_RP_350.1-RpL3i-XI-F3) were found in putative ORFs while CTG_RP_146.1-RpL3i-III-F3 was probably within the 3 -unstranslated region. None of these contigs correspond to known ORFs.

In conclusion, ESTs provide a valuable resource for gene discovery related to the regulation of reproduction mode in aphids. The next step will be the use of these ESTs for cDNA array-based technologies and comparative hybridizations in order to identify aphid 


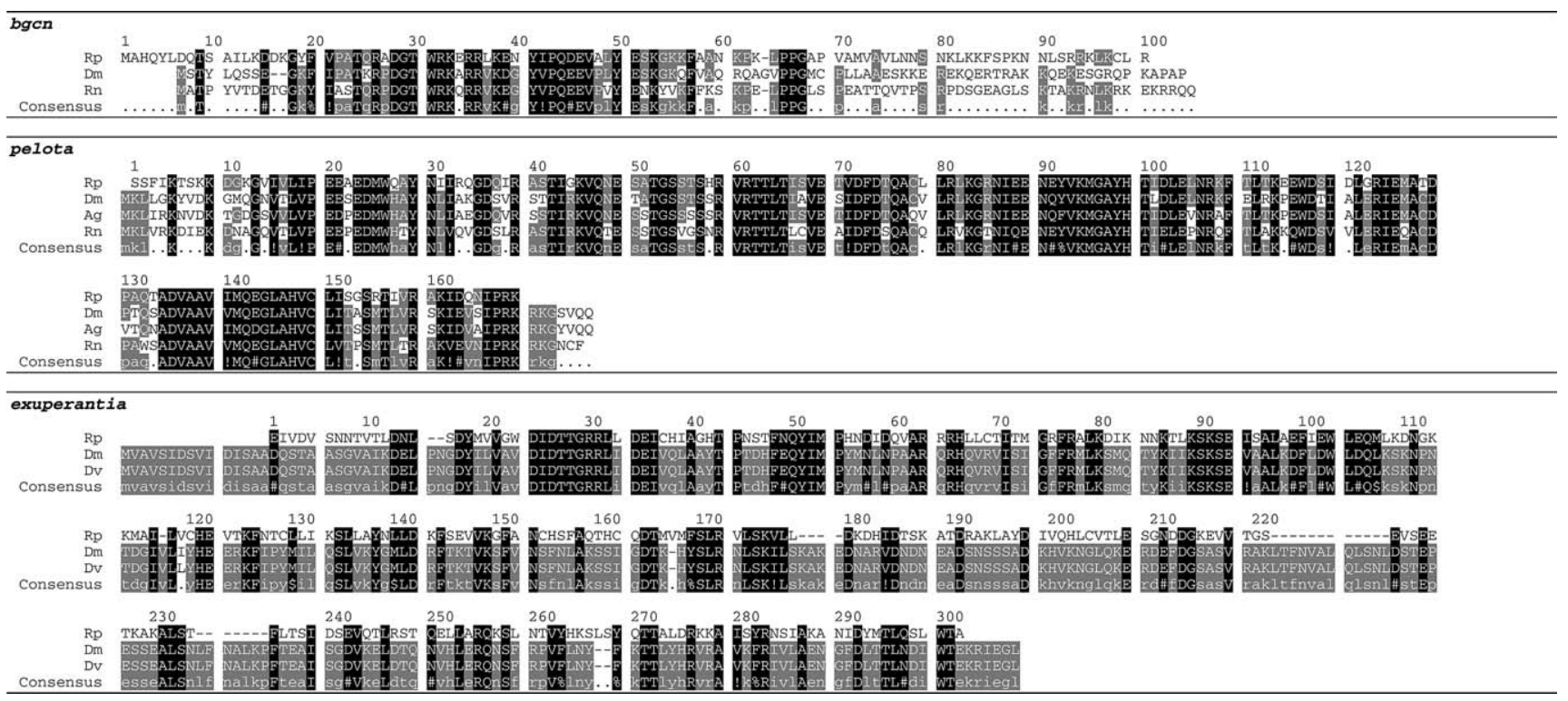

Fig. 3. Comparison of the predicted amino acid sequences of three $R$. padi cDNA inserts with other animal sequences. The $R$. padi sequences are shown on the upper lines in single letter code. The predicted amino acid sequences of Anopheles gambiae (Ag), Drosophila melanogaster (Dm), Drosophila viridis $(\mathrm{Dm})$ and Rattus norvegicus $(\mathrm{Rn})$ are shown below in optimal alignment (Corpet, 1998). Common amino acids are shown in black (present in all compared sequences) or grey (present in the majority of the sequences). Gaps are indicated (-).

genes involved in the switch between the development of asexual and sexual morphs. The present data rep- resent a first step towards the identification and annotation of transcript complements in aphids.

Table 3

R. padi contigs sequence similarities from the "no hit" category after a BLASTX, filter off

\begin{tabular}{|c|c|c|c|c|c|}
\hline Contig name & Protein homologue & Species & Accession number & $E$-value & Feature \\
\hline CTG_RP_1.1-RpL3i-I-D6 & Ribosomal protein L41 & Drosophila melanogaster & Q962S2 & $7 \times 10^{-7}$ & $\mathrm{R} / \mathrm{K}$ rich \\
\hline CTG_RP_15.1-RpL3i-III-C8 & Putative VrrB & Bacilus subtilis & Q9KI89 & $3 \times 10^{-19}$ & $\mathrm{H}$ rich \\
\hline CTG_RP_18.1-RpL3i-IX-G10 & Hypothetical protein & Anopheles gambiae & Q7QEH2 & $8 \times 10^{-7}$ & none \\
\hline CTG_RP_26.1-RpL3i-I-A12 & Histone $\mathrm{H} 1$ & Triticum aestivum & P27806 & $8 \times 10^{-12}$ & $P$ rich \\
\hline CTG_RP_28.1-RpL3i-III-G9 & $\begin{array}{l}\text { Cold and drought-regulated } \\
\text { protein CORA }\end{array}$ & Medicago sativa & Q07202 & $5 \times 10^{-15}$ & G rich \\
\hline CTG_RP_35.1-RpL3i-I-D11 & Hypothetical protein & Caenorhabditis elegans & Q20013 & $2 \times 10^{-9}$ & none \\
\hline CTG_RP_56.1-RpL3i-VI-H8 & $\begin{array}{l}\text { Peptidyl-prolyl cis-trans } \\
\text { isomerase }\end{array}$ & Spodoptera frugiperda & Q26486 & $3 \times 10^{-10}$ & none \\
\hline CTG_RP_132.1-RpL3i-III-A9 & Mucin 5 & Homo sapiens & Q8WWQ4 & $7 \times 10^{-6}$ & none \\
\hline CTG_RP_134.1-RpL3i-III-B12 & Hypothetical protein & Anopheles gambiae & Q7PNM6 & $8 \times 10^{-8}$ & none \\
\hline CTG_RP_160.1-RpL3i-IV-D12 & $\begin{array}{l}\text { Orotidine } 5^{\prime} \text {-phosphate } \\
\text { decarboxylase }\end{array}$ & Buchnera aphidicola & Q8K9Q1 & $2 \times 10^{-12}$ & none \\
\hline CTG_RP_172.1-RpL3i-IV-G5 & Hypothetical protein & Anopheles gambiae & Q7QII3 & $2 \times 10^{-13}$ & Q rich \\
\hline CTG_RP_174.1-RpL3i-IV-G8 & $\begin{array}{l}\text { DNA mismatch repair protein } \\
\text { mutL }\end{array}$ & Buchnera aphidicola & Q8K913 & $7 \times 10^{-19}$ & $\mathrm{~K}$ rich \\
\hline CTG_RP_179.1-RpL3i-IX-A10 & PmbA protein homolog & Buchnera aphidicola & Q8KA30 & $5 \times 10^{-17}$ & none \\
\hline CTG_RP_206.1-RpL3i-IX-G5 & Hypothetical protein & Danio rerio & Q7ZU84 & $4 \times 10^{-16}$ & $\mathrm{E} / \mathrm{D}$ rich \\
\hline CTG_RP_225.1-RpL3i-V-D5 & $\begin{array}{l}\text { 90-kDa heat shock protein } \\
\text { HSP83 }\end{array}$ & Spodoptera frugiperda & Q9GQG6 & $8 \times 10^{-11}$ & none \\
\hline CTG_RP_248.1-RpL3i-VI-C1 & Trigger factor $(\mathrm{TF})$ & Buchnera aphidicola & Q8K991 & $2 \times 10^{-16}$ & $\mathrm{~K}$ rich \\
\hline CTG_RP_266.1-RpL3i-VI-H1 & Hypothetical protein & Drosophila melanogaster & Q9W1R2 & $4 \times 10^{-16}$ & G rich \\
\hline CTG_RP_293.1-RpL3i-VIII-E11 & DNA gyrase subunit A & Buchnera aphidicola & Q8K9W2 & $2 \times 10^{-14}$ & none \\
\hline CTG_RP_314.1-RpL3i-X-C12 & Nucleoplasmin-like protein & Drosophila melanogaster & Q27415 & $6 \times 10^{-6}$ & E rich \\
\hline CTG_RP_326.1-RpL3i-X-G5 & Ribosomal protein S3A & Spodoptera frugiperda & Q95V35 & $2 \times 10^{-6}$ & $\mathrm{~K}$ rich \\
\hline CTG_RP_334.1-RpL3i-XI-B11 & Hypothetical protein & Drosophila melanogaster & Q9VNX6 & $1 \times 10^{-7}$ & G rich \\
\hline CTG_RP_339.1-RpL3i-XI-D1 & Chorion protein s 18 precursor & Ceratitis capitata & Q9NFX7 & $5 \times 10^{-8}$ & $\mathrm{~A} / \mathrm{S}$ rich \\
\hline CTG_RP_354.1-RpL3i-XI-G5 & Probable nucleoporin Nup54 & Drosophila melanogaster & Q9V6B9 & $2 \times 10^{-7}$ & Q rich \\
\hline
\end{tabular}


CTG_RP_28.1-RpL3i-III-G9

GGGGACAGTATACATCACACTTTCAAAGACGAATATTCAGTAGTCTCAAGAATCATGAAATCTTACACAGCGATA TTAGCTTTGTGTTTTGTCGTTCTCGTAATGACTCAACAAGCTACTTCAGAACCAGCTCCCGAACCACGCAAGAAT GATGGTGGTGGTGGTGGTGGTGGTGGTGGAAATCACCATGGAACTGGTGGAAATTATGGAAATGGAAATT ACGGACATGGACATGGTGGACACGGTGGACACGGTGGCAACGGACATAATACACACGGAAGTAGCGGACATGGAC AACACGGACACGGAGGTGGCGGACACGGACACGGAGGACATCATTAAATTTAAAACAATTTCATTTTCATCCAGT ACAATAATATAAAAAAAAACTATTATTTTTTTTCTTATCAATCTATGTATTATCTTTAATGCAAAATCCCGAATA AACAATAATTTCTCATGGAAATTTTCACCTA

CTG_RP_194.1-RpL3i-IX-E4

GGGGATATCGTTTATTATTATTATTATTATTATAAATTTTTTTTCGTTTCGTGTTTTCCGTTTTCGGCGTC CACCGCCGTTCGCCGCCAACGGCTGTCGCGTCGCCTTACGACAACGATAACGACGACGACAACAACAACAACGGC GATAAACCACAACAAACCGACAACGACGGTGCGCGTGTTGTTCCGAGTACGACCGCACGGCATTCGCTGCTCCGT CCGTCCGTCGCGGTGTCCGCGTCCGATGGGGATATCAACGTGCAC

CTG_RP_146.1-RpL3i-III-F3

GGGGACTGCATGGACCCAGAAGATGAAGACGGAATGATCCCTTATGTCCCGTTCGTAAAAAAAGTGATGGTTCGC CTGAGCGACATGAAGTAAATTCCATTTTAAGCGTTTAAAGTTAAAAAAAAAACATTAAAAAATTTAAACTACCCG GACCATTATCCCGTTTCTGGCCAAAGTTTGCGGAAAGCCCGTACCGGCCGACGACAACCCATTCAACAAGTAAAA CTACACGCGCATCGCTCCGACAAAAGCAAATACACGTNATTATTTATTTA TTATTATTATTAATATAATTATT ATAATTGCAAAAAAAAAAAA

CTG_RP_350.1-RpL3i-XI-F3

GGGGTTACAATGTTTACCCGAACCGCCGGACAGTTGGCTGGCCAGTTGTTTACGTAAATCGATCTTGCGCGACAC CTGCGGCGGTGGTGGTGGCGGCTCCGCGATTGACGGAGTGACGACGATGGTGGCGGCGGGCATGGAGGTGGTG GTTACGTTGGTTGTAGCAGTAGTGGTGGTGGTGTTGTTGTACGTTGACATATGGGCCTCCTCGACTTTGACAG AACGGTTTAACATTTTCATAGAATGTTCTTCCATCCATCTCTATAAAAAAATATCAAACGAAATATTGTGTTTAC TTTAAAA

Fig. 4. Microsatellite sequences found in four contigs of R. padi. Microsatellites are underlined in bold.

\section{Acknowledgments}

We thank Gérard Devauchelle (INRA, St Christolles-Alès, France) for giving us access to unpublished data on S. frugiperda ESTs, Wayne Hunter (USDA, Fort Pierce, Florida) for sharing EST data and Claude Rispe (INRA Rennes, UMR BiO3P) for reading the manuscript. This work has been supported by INRA ("Santé des Plantes et Environnement" Department) and an INRA postdoctoral grant to B. Sabater-Muñoz. Morgan Perennou, Erwan Corre and Antoine Lostanlen (CNRS Roscoff, OUEST-Genopole ${ }^{\mathbb{R}}$, France) are acknowledged for their advice in EST sequencing. We thank Julien Elie for his technical help in PCR amplification.

\section{References}

Adham, I.M., Sallam, M.A., Steding, G., Korabiowska, M., Brinck, U., Hoyer-Fender, S., Oh, C., Engel, W., 2003. Disruption of the pelota gene causes early embryonic lethality and defects in cell cycle progression. Molecular Cell Biology 23, 1470-1476.
Baumann, P., Baumann, L., Lai, C.Y., Rouhbakhsh, D., Moran, N.A., Clark, M.A., 1995. Genetics, physiology and evolutionary relationships of the genus Buchnera: intracellular symbionts of aphids. Annual Review Microbiology 49, 55-94.

Blackman, R.L., 1987. Reproduction, cytogenetics and development. In: Minks, A.K., Harrewijn, A.P. (Eds.), Aphids, their biology, natural enemies and control, 2A. Elsevier, Amsterdam, Oxford, New York, Tokyo, pp. 163-195.

Corpet, F., 1998. Multiple sequence alignment with hierarchical clustering. Nucleic Acids Research 16, 10881-10890.

Dixon, A.F.G., 1998. Aphid ecology: an optimization approach, second ed. Chapman \& Hall, London.

Domazet-Loso, T., Tautz, D., 2003. An evolutionary analysis of orphan genes in Drosophila. Genome Research 13, 2213-2219.

Ewing, B., Hillier, L., Wendl, M.C., Green, P., 1998. Base-calling of automated sequencer traces using phred. I. Accuracy assessment. Genome Research 8, 175-185.

Ewing, B., Green, P., 1998. Base-calling of automated sequencer traces using phred. II. Error probabilities. Genome Research 8, 186-194.

Glémet, E., Codani, J.J., 1997. LASSAP, a Large Scale Sequence Comparison Package (note: LASSAP is now Biofacet $\left.{ }^{(\mathbb{m}}\right)$. Computational Applied Bioscience 13, 137-143.

Gray, S., Gildow, F.E., 2003. Luteovirus-aphid interactions. Annual Review Phytopathology 41, 539-566.

Hardie, J., Nunes, M.V., 2001. Aphid photoperiodic clocks. Journal Insect Physiology 47, 821-832. 
Hunter, W.B., Dang, P.M., Bausher, M.G., Chaparro, J.X., McKendree, W., Shatters, R.G., McKenzie, C.L., Sinisterra, X.H., 2003. Aphid biology: expressed genes from the alate Toxoptera citricida, the brown citrus aphid. Journal Insect Science 3, 23.

Landais, I., Ogliastro, M., Mita, K., Nohata, J., Lopez-Ferber, M., Duonor-Cérutti, M., Shimada, T., Fournier, P., Devauchelle, G., 2003. Annotation pattern of ESTs from Spodoptera SF9 cells and analysis of the ribosomal protein genes reveal insect-specific features and unexpectedly low codon usage bias. Bioinformatics 19, 2343-2350.

Macdonald, P.M., Luk, S.K., Kilpatrick, M., 1991. Protein enriched by the exuperantia gene is concentrated at sites of bicoid mRNA accumulation in Drosophila nurse cells but not in oocytes or embryos. Genes Development 5, 2455-2466.

Mita, K., Morimyo, M., Okano, K., Koike, Y., Nohata, J., Kawasaki, H., Kadono-Okuda, K., Yamamoto, K., Suzuki, M.G., Shimada, T., Goldsmith, M.R., Maeda, S., 2003. The construction of an EST database for Bombyx mori and its application. Proceedings National Academy Science USA 100, 14121-14126.

Ohlstein, B., Lavoie, C.A., Vef, O., Gateff, E., McKearin, D.M., 2000. The Drosophila cystoblast differentiation factor, benign genial cell neoplasm, is related to DExH-box proteins and interacts genetically with bag-of-marbles. Genetics 155, 1809-1819.

Ramos, S., Moya, A., Martinez-Torres, D., 2003. Identification of a gene overexpressed in aphids reared under short photoperiod. Insect Biochemistry Molecular Biology 33, 289-298.

Samson, D., Legeai, F., Karsenty, E., Reboux, S., Veyrieras, J.B., Just, J., Barillot, E., 2003. GenoPlante-Info (GPI): a collection of databases and bioinformatics resources for plant genomics. Nucleic Acids Research 31, 179-182.

Shigenobu, S., Watanabe, H., Hattori, M., Sakaki, Y., Ishikawa, H., 2000. Genome sequence of the endocellular bacterial symbiont of aphids Buchnera sp APS. Nature 407, 81-86.

Simon, J.-C., Dedryver, C.A., Pierre, J.S., 1991. Identifying bird cherry-oat aphid Rhopalosiphum padi emigrants, alate exules and gynoparae: application of multivariate methods to morphometric and anatomical features. Entomologia Experimenta Applicata 59, 267-277.

The Gene Ontology Consortium, 2001. Creating the gene ontology resource: design and implementation. Genome Research 11, 1425-1433. 